\title{
TRIPLE FRONTERA: MEDIOS Y REPRESENTACIONES UNA PERSPECTIVA DESDE LO LOCAL
}

\author{
Tríplice Fronteira: meios e representações \\ Uma perspectiva desde o local \\ Triple Frontier: media and representation \\ A local perspective
}

\section{Resumen}

Aníbal Orué Pozzo

Centro de Estudios de las Relaciones Paraguay-Brasil Escuela de Posgrado - Universidad Nacional del Este (UNE) aorue@sce.cnc.una.py

El texto analiza la construcción de una narrativa desde lo local - Triple Frontera: Ciudad del Este (Paraguay), Foz do Iguaçu (Brasil) y Puerto Iguazú (Argentina) - en relación a la narrativa de medios de comunicación de países del Norte hegemónico. Partiendo de dos cortes temporales - el atentado a las torres gemelas en New York en el 2001, y el golpe parlamentario contra el presidente Fernando Lugo en el 2012 - el artículo desarrolla una perspectiva de análisis desde lo local, y cómo y de qué manera esta narrativa cuestiona o desafía narrativas de medios de comunicación de países del Norte.

Palabras clave: Triple Frontera. Diferencia colonial. Narrativas locales.

\section{Resumo}

O texto analisa a construção de uma narrativa desde o local - Tríplice Fronteira: Ciudad del Este (Paraguai), Foz do Iguaçu (Brasil) e Puerto Iguazu (Argentina) - em relação á narrativa de meios de comunicação de países do Norte hegemônico. A partir de dois cortes temporais atentado ás Torres Gêmeas em Nova Iorque no 2001, e o golpe parlamentar contra o presidente Fernando Lugo no Paraguai no 2012 - o artigo desenvolve uma perspectiva de análise desde o local, e como y de que maneira esta narrativa questiona ou desafia narrativas de meios de comunicação de países do Norte.

Palavras chaves: Tríplice Fronteira. Diferença colonial. Narrativas locais.

\begin{abstract}
This article analizes the construction of a local narrative - Triple Frontier: Ciudad del Este (Paraguay), Foz do Iguacu (Brazil) and Puerto Iguazú (Argentina) - related to the Northern countries media narratives. From two different times - the World Centre attack in New York, 2001, and the parliamentary coup against President Fernando Lugo in Paraguay, 2012 - this writing develop a local perspectives analyze and how and in what form this narratives question or defies media from the Northern countries.
\end{abstract}

Key words: Triple Frontier. Colonial difference. Local narratives. 


\section{INTRODUCCIÓN}

El presente trabajo tiene por objetivo estudiar y analizar las construcciones socioculturales que los medios de comunicación locales realizan e impulsan acerca del espacio social denominado de Triple Frontera, constituido por las ciudades de Puerto Iguazú (Argentina), Ciudad del Este (Paraguay) y Foz do Iguaçu (Brasil). Para tal efecto se analizará medios externos a la región, asimismo un medio impreso local, el diario Vanguardia de Ciudad del Este.

Gran parte de los estudios e interpretaciones desarrolladas sobre la Triple Frontera, provienen de contenidos de medios internacionales, principalmente norteamericanos y europeos, asimismo de medios impresos de circulación nacional en los países que forman parte de esta región. Desde esta perspectiva la Triple Frontera es construida como un espacio donde reina y se instala el narcotráfico, el tráfico de armas y de personas, siendo una de las principales características de este espacio la de ser lugar de todo tipo de ilícitos y de prácticas ilegales muy alejadas del control de los estados nacionales. Desde inicio de la década de los '90 del siglo pasado, la Triple Frontera fue construida por los medios de comunicación "externos" a la región bajo estas perspectivas. Inclusive, medios de comunicación localizados en países hegemónicos terminan reproduciendo caracterizaciones basadas en intereses y percepciones de agencias oficiales norteamericanas de seguridad. Tal situación se da con mayor intensidad desde los atentados en 1992 a la embajada de Israel en Buenos Aires, y luego, en 1994 a la sede de la Asociación Mutual Israelita, también ubicada en Buenos Aires. Esto se profundiza tras el atentado a las Torres Gemelas en New York, en el año 2001.

Por otro lado, y desde los medios de comunicación locales, siempre se ha dado una resistencia y postura distinta a aquellas expresadas por los grandes medios hegemónicos internacionales, asimismo a los de circulación nacional en los países que conforman la Triple Frontera. Desde esta perspectiva, lo local termina cuestionando tanto las representaciones construidas por los medios hegemónicos internacionales, asimismo aquellas desarrolladas por los medios nacionales. Esta constatación empírica, nos lleva a pensar y desarrollar modelos interpretativos por un lado - y bajo una misma matriz teórico-cultural-, o a perspectivas diferentes - desde una episteme diferente -, acerca de las construcciones socioculturales y representaciones impulsadas por los medios de comunicación locales, nacionales e internacionales, como espacio de disputa de significados y de representaciones, asociadas también a disputas sobre diversos aspectos relacionados al poder, sea éste local, nacional o 
internacional. Pero no solo disputas relacionadas al poder; también disputas epistémicas, opciones que colocan el conocimiento y la subjetividad del propio ser, en una centralidad distinta a aquella impulsada por la modernidad eurocéntrica.

\section{PRIMERA PARTE}

\subsection{Medios “externos” a la Triple Frontera: construcciones globales y sus limitaciones}

Uno de trabajos pioneros en este campo de trabajo de construcciones y representaciones de la Triple Frontera a partir del análisis de contenidos de medios internacionales, es el de Montenegro \& Giménez Béliveau (2010, p.15): tratando acerca "de la construcción social del espacio, en la singularidad de un territorio de frontera", "el eje del trabajo descansa en el análisis de las representaciones sociales que sobre la Triple Frontera construyen diversos actores, cuyas experiencias y prácticas coinciden o trascienden la localización en ese territorio".

Para tal efecto, uno de los aspectos analizados y estudiados es cómo o de qué manera las miradas sobre la Triple Frontera impulsadas por los medios de comunicación, poseen una eficacia en la transmisión de sus definiciones. Así,

La forma en que la prensa se refiere a la TF supone la existencia de un ámbito con características propias, irreductible a las lógicas culturales, legales, económicas o políticas de cada uno de los tres países. En la visión reificada de algunos medios, uno de las reglas de la dinámica de la TF consistiría justamente en carecer de una dinámica reglada. En tanto "tierra sin ley", la zona es retratada como concentrando la suma total de atributos negativos de los tres países: corrupción, lavado de dinero, tráfico de influencias, dimisión del estado, arbitrariedad, situación permanente de crisis, inseguridad y riesgo (MONTENEGRO \& GIMENEZ BELIVEAU, 2010, p.43).

\subsubsection{Medios norteamericanos}

La investigación de las investigadoras abarca el estudio de contenidos de publicaciones norteamericanas, asimismo medios impresos de circulación nacional argentinos y brasileños. Con relación a medios norteamericanos, señalan que "La cobertura periodística de la TF por parte de los medios de prensa estadounidenses se remonta a finales de la década de los noventa y muestra una homogeneidad de perspectiva que son reapropiadas o parcialmente repelidas por los diarios paraguayos, brasileños y argentinos" (MONTENEGRO \& GIMENEZ BELIVEAU, 2010, p 43). 
Estos medios de comunicación del norte inician la cobertura de la zona de la Triple Frontera primero en forma episódica para, luego de los atentados a las Torres Gemelas en setiembre de 2001, tornarse un tema sistemático, según sostienen. Esto incluyó enviados especiales, asimismo notas realizadas por especialistas en América Latina. Pero, básicamente, según apuntan las autoras, fue un trabajo a partir de fuentes secundarias. Al analizar periódicos tales como el Washington Post, The Washington Times y el New York Times, las autoras destacan que en los últimos años, "la mirada externa sobre la TF, se plasmó en una matriz de discurso homogéneo y recurrente", siendo que las primeras informaciones se circunscriben a las sospechas de que "árabes residentes en la zona estaban implicados en los atentados perpetrados en Buenos Aires en la embajada de Israel en 1992 y a la sede de la Asociación Mutual Israelita en 1994” (MONTENEGRO \& GIMENEZ BELIVEAU, 2010, p. 47). De esta manera, e inicialmente,

El análisis de las notas periodísticas aparecidas en algunos medios estadounidenses revela la caracterización de la TF como siendo, desde hace tiempo, una "tierra sin ley", una región remota y "extraña" sobre la cual los tres países, en cuya interrelación se localiza, no han podido o querido establecer ningún tipo de orden.” (MONTENEGRO \& GIMENEZ BELIVEAU, 2010, p. 47).

Luego de los ataques del 11 de setiembre, The Washington Times, órgano de estrechas relaciones con la Secta Moon, suponía "que la TF, de por sí porosa a la corrupción y a la economía del mercado negro, podía ser un lugar conveniente desde el cual se planeen o financien actividades terroristas." (Montenegro \& Giménez Béliveau, 2010, p. 50) Poco tiempo después, este medio, según las autoras, al insistir en la alta cifra de árabes en la región - mencionando entre 25 mil a 30 mil libaneses, palestinos y sirios -, apuntan la certeza de sus "vínculos con organizaciones terroristas." Citando como fuente al Centro para la Investigación del Terrorismo con sede en Virginia, USA, el medio continúa afirmando que,

[...] la TF era una "área de entrenamiento para matar americanos y judíos". El director de de esa institución, Walter Purdy, habría sostenido que el jefe militar en la región era Assad Barakat, "poderoso propietario de comercios en Ciudad del Este" y que la zona, al carecer de controles por parte de los gobiernos, se había transformado en "atmósfera propicia para las operaciones terroristas" y en un lugar donde "los terroristas de Al Qaeda se mueven libremente" (MONTENEGRO \& GIMENEZ BELIVEAU, 2010, p. $51)$.

A lo largo del 2002, el contenido de los artículos publicados en The New York Times y The Washington Post, según las investigadoras, estaban en perfecta sintonía "con la visión 
que el Departamento de Estado de Estados Unidos había transmitido sobre la región.” (p. 51). De esta manera, destacan que,

\begin{abstract}
A partir de 2001 las notas comenzaron con una descripción de la región coincidente con la que algunos organismos estadounidenses presentaron en informes oficiales. Posteriormente, y dando por sentada la presencia de grupos terroristas, el eje temático de los artículos se desplazó hacia el monitoreo de los controles estatales necesarios de implementar en la frontera, siguiendo de cerca las vicisitudes de acciones particulares de gobiernos como el de Paraguay o, incluso, imaginando escenarios más eficaces de acción multilateral (MONTENEGRO \& GIMENEZ BELIVEAU, 2010, p. 62).
\end{abstract}

En este sentido, uno de los aspectos que se tornó central en los contenidos de estos medios impresos es el destaque a la idea de la escasa capacidad de los gobiernos locales "por controlar un área vista como prácticamente independiente, una "zona gris", un "espacio sin estado" y "sin ley", apropiado por las mafias étnicas, los carteles internacionales y la libre circulación de bienes ilícitos" (MONTENEGRO \& GIMENEZ BELIVEAU, 2010, p. 62). Las autoras concluyen que esta forma de presentar contenidos es sin duda ampliamente sustentada en aspectos y situaciones localizadas en ese país. Así,

Sin duda, la TF ingresó en la agenda del periodismo post 11 de setiembre y, en tal sentido, es posible pensar que las notas tuvieron como destinatarios a los lectores corrientes de esos periódicos, probablemente en el contexto más amplio del "impulso patriótico" que algunos medios siguieron en apoyo a los discursos estratégicos que los organismos oficiales de Estados Unidos comenzaban a implementar, en el marco de su programa de lucha contra el terrorismo global (MONTENEGRO \& GIMENEZ BELIVEAU, 2010, p. $63)$.

\title{
1.1.2 Medios argentinos
}

Continuando con la investigación citada más arriba, las escritoras analizan y estudian contenidos de dos medios impresos argentinos de circulación nacional, Clarín y La Nación, en el período 2001-2005. Es interesante el giro que estos medios emprenden en relación al tema de la Triple Frontera. La investigación señala que,

Al colocar en perspectiva temporal los discursos y argumentos que allí aparecieron, es posible notar un desplazamiento en la forma de referirse a la región. En general, la TF fue primero construida por esos medios en un sentido similar al que encontrábamos en la prensa internacional para, posteriormente, ser presentada como espacio que suscitaba visiones opuestas, al tenerse en cuenta la voz de otros actores y sus denuncias acerca 
de la "demonización de la región". (MONTENEGRO \& GIMENEZ BELIVEAU, 2010, p. 67).

Las primeras notas de estos medios posterior al 11 de setiembre de 2001, acompañaban las sospechas de terrorismo levantado por medios hegemónicos norteamericanos. Sin embargo, en la segunda semana de análisis,

[...] ya se presentaban en Clarín notas realizadas por enviados especiales a la zona. Lo que llamaba la atención a uno de los periodistas destacados en el lugar era precisamente la repercusión escasa que lo que se decía sobre la TF tenía entre sus habitantes. Es así que uno de los artículos señala que los lugareños se burlaban en la supuesta existencia de células dormidas, la presencia de adeptos de Bin Laden o la pertenencia de los inmigrantes a grupos terroristas (MONTENEGRO \& GIMENEZ BELIVEAU, 2010, p. 69).

De esta manera, existe un desplazamiento de los ejes temáticos, según las autoras, que permitieron que las noticias sobre la región pasen de las denuncias de la presencia de células dormidas a las sospechas de células financieras de apoyo al terrorismo, para finalmente recaer en las relaciones entre recursos naturales e intereses internacionales. América del Sur estaba comenzando a mudar, y la presencia desde el 2003 de gobiernos progresistas y de centro izquierda se expresaba, de alguna manera, en los contenidos de estos medios, al desplazarse también el eje de los intereses de los medios argentinos en la región.

Se tiene entonces, desde los medios argentinos, una situación en la cual inicialmente acompañan las posturas y contenidos de los medios norteamericanos para, posteriormente comenzar levemente a cuestionarlos y reorientar estas informaciones hacia otros temas, sumamente críticos en la región: recursos naturales. De la unidireccionalidad de los medios norteamericanos a la ambigüedad de los medios nacionales argentinos. ¿Y los medios locales?

\subsection{El lugar de enunciación en la práctica periodística}

Antes de avanzar en el estudio de las construcciones discursivas de los medios locales, me gustaría referirme a una de las cuestiones que considero clave en el meta discurso y la narrativa periodística: el lugar de enunciación.

Desde las teorías feministas se ha desarrollado el concepto de que ninguna interpretación es neutra. Tras reconocer este sesgo, que responden con un ejercicio de lectura intencionada entre líneas o a contrapelo, desde otro espacio discursivo, esta teoría ha demostrado que la escritura, publicación y circulación de obras literarias - entre las cuales podemos considerar la narrativa periodística - están inevitablemente marcadas por el género 
(GULUBOV, 2011). Entre otras cuestiones, esto implica que los discursos producen activamente lugares de enunciación y posiciones subjetivas que tienen consecuencias materiales y simbólicas, individuales y colectivas. Las teorías feministas están atentas, en un primer momento, a las formas androcéntricas (por ejemplo, en el uso del género masculino como neutro) de la propia lengua y las consecuencias que esto tiene en los procesos de significación. Pero, sobre todo, analizan las condiciones histórico-sociales de la producción y las condiciones histórico-sociales de la interpretación de los discursos, entendidos como sistemas de representación, y su relación con las prácticas sociales, considerando que los textos literarios participan activamente en estos procesos de interacción social. Desde los distintos lugares de enunciación la crítica feminista fue construyendo la necesaria diversidad de enfoques críticos de la colonialidad (BIDASECA \& VAZQUEZ LABA, 2013). En el caso de la narrativa periodística, entiendo que el lugar de enunciación - países hegemónicos en este caso -, define la forma de pensar y sobre todo de construir el sujeto representado y narrado. Podemos observar, desde los textos presentados por Montenegro \& Giménez Béliveau (2010) que los mismos construyen una narrativa colonialista, degradando y, al mismo tiempo, asumiendo inferioridades de los sujetos representados en la Triple Frontera. Por otro lado, "la denominación es a la vez un modo de fijar una frontera y también de inculcar repetidamente una norma" (BUTLER, 2008, p.26).

Todo esto nos muestra la necesidad de pensar el conocimiento como geopolítica en vez de pensarlo como un lugar universal al que todos tienen acceso, pero del que, “desafortunadamente, solo algunos tienen la llave" (MIGNOLO, 2003, p.21). Para Mignolo,

los lugares de enunciación generan, por un lado, las geopolíticas del conocimiento en sus diversas y complejas relaciones con los diversos imperialismos occidentales, diversos pero mancomunados en su pertenencia y contribución a la historia del capitalismo (Wallerstein, Arrighi), y, por otro, las condiciones para la toma de decisiones éticas, políticas y epistémicas para la descolonización del saber y la contribución a crear un mundo críticamente cosmopolita (MIGNOLO, 2003, p. 54).

Los centros hegemónicos del capitalismo como lugares de enunciación desde los cuales se producen y manufacturan los textos y narrativas periodísticas que Montenegro \& Giménez Béliveau presentan, impulsan una perspectiva de mundo estrechamente relacionada a dicho poder, generan una "geopolítica del conocimiento" como lo expresaba más arriba Mignolo. Lo que es posible observar en los textos periodísticos de los medios norteamericanos destacados por las investigadoras es: 
1. Un conocimiento y un ordenamiento jurídico-político perteneciente a países europeos y a USA, inexistente en la Triple frontera.

2. La ilegalidad y el tráfico de todo tipo, como intrínsecamente asociado a países del Tercer Mundo, subdesarrollados o incivilizados.

3. Una población no perteneciente a la europea o de USA, inferior, sujeta a todo tipo de estadios no civilizatorios.

4. La necesidad de llevar "civilización” a la región.

Parto de la constatación de que todos estos proyectos surgen del entendimiento de que no se trata de "diferencias culturales", sino de "diferencias coloniales". Es decir, diferencias coloniales que fueron construidas por el pensamiento hegemónico en distintas épocas desde la llegada del colonizador europeo. La misma destaca las faltas y los excesos de las poblaciones no europeas -y actualmente también no norteamericanas -, como la población paraguaya, argentina, brasileña, árabe, paquistaní, india, aborigen y otras de la Triple Frontera, que es necesario corregir y civilizarlas. Estas diferencias coloniales fueron presentadas inicialmente como "diferencias culturales" siendo que en realidad enmascaran y ocultan la diferencia de poder, es decir, la colonialidad del poder. (Mignolo, 2003) De esta forma, el periodismo del Norte en relación al Sur global tiene que ser entendido no como una diferencia cultural, sino como una práctica que se piensa desde la diferencia colonial. Es decir, no transformar estas diferencias coloniales en objeto de estudio, estudiándolas desde la perspectiva epistémica de la modernidad, sino desde la opción de la diferencia colonial, como construcción de subjetividades.

Esto queda mucho más claro cuando estudiamos y trabajamos las experiencias locales que cuestionan y critican aquellas presentadas por el periodismo hegemónico internacional como experiencias, prácticas y entendimientos universales. De esta manera, una mirada y rescate de las experiencias locales, introduce una perspectiva y opción diferente a aquella practicada por el periodismo estudiado y analizado por Montenegro y Giménez Béliveau.

\section{SEGUNDA PARTE}

\subsection{Lo local como estrategia periodística otra}

En los últimos años, esta zona de frontera ha sido visualizada desde diversas perspectivas, prejuicios y estereotipos, por un lado, pero también ha sido reconocida como espacio social de construcción de identidades en tránsito, identidades híbridas, de culturas en movimiento, de zona de interculturalidad, etc.. Una permanente tensión entre estas 
caracterizaciones y entendimientos ha llevado a este territorio y a su población, que congrega alrededor de 650 mil personas - Foz do Iguaçu (Brasil), Ciudad del Este (Paraguay) y Puerto Iguazú (Argentina) -, a convivir con estas interpretaciones en un tiempo social ambiguo e indeterminado, aunque en permanente redefinición.

Sin embargo, la construcción de uno u otro énfasis de entendimiento y caracterización, implica la puesta en escena de varios agentes sociales e instituciones que, o cosifican esta versión o la cuestionan desde otras perspectivas, que no las hegemónicas y occidentales.

Esta segunda parte busca reconstruir, desde una matriz teórica crítica, el camino seguido hacia estas conceptualizaciones, centrándose, inicialmente en la práctica periodística de la frontera, desde Paraguay. De esta manera, se asume que el medio de comunicación, en el tiempo, logra imponer o negociar ciertas representaciones e imaginarios sociales que llevan a sus receptores o lectores a determinados entendimientos que, aunque fragmentarios, apuntan en el tiempo hacia una cristalización móvil de los mismos.

Por otro lado, la practica social generada y desarrollada en esta región, el continuo intercambio cultural, las migraciones intermitentes, espontáneas y cortas en el tiempo, además de una reconfiguración del espacio, constituyen elementos que, de alguna manera, cuestionan el entendimiento tradicional de la modernidad que intenta definir un determinado estadonación a partir de su territorio claramente definido, de su lengua vernácula, asimismo de una cultura determinada y compartida en el tiempo. Todos estos elementos están, en este espacio de las tres fronteras, en permanente mutación y movimiento. En este contexto, la institución del periodismo de frontera en Paraguay, sus espacios de consumo y distribución, serán abordados como pistas para reconstruir los imaginarios y representaciones que pesan sobre esta espacialidad, su población, asimismo sobre su cultura, como práctica "contra hegemónica" y cuestionadora a aquella de los medios hegemónicos internacionales y nacionales. O, si se prefiere, desde la perspectiva de una diferencia colonial.

\subsection{Perspectiva de trabajo}

La construcción de representaciones e imaginarios es un complejo y permanente proceso social en el cual están presentes varias y diversas aristas y entendimientos. En distintos momentos, estos conceptos han sido trabajados por investigadores en las ciencias sociales y humanas en Paraguay, entre los cuales es posible citar a Domínguez (1946), González (1935), López (2003), Orué Pozzo (2008), entre otros. Sin embargo, es importante destacar que no existe una única y exclusiva forma o manera de entender y de orientar las 
investigaciones desde estas perspectivas. No obstante, podemos ponernos de acuerdo en algunos puntos básicos, sin que éstos sean únicos y exclusivos.

Partiendo de Bauman (1992), y de manera heurística, tenemos que una de las formas de presentar y organizar estos procesos de representación y construcción de imaginarios es el entendimiento de considerarlos como socialmente construidos, enraizados en relaciones sociales y también producidos y reproducidos en la vida social. De esta manera considerar o pensar la lengua, la literatura, la música u otros aspectos de la cultura popular, por ejemplo, como sistemas autónomos es a lo sumo una abstracción analítica distanciada de su fundamental naturaleza cual es la de ser una práctica social. Desde este entendimiento no solamente las representaciones e imaginarios son socialmente construidos, sino que también se producen y reproducen en todo acto comunicativo de intercambios social y simbólico.

Un segundo entendimiento que presento como punto de partida, es aquel que considera a las representaciones e imaginarios presentes en diversas formaciones sociales como las artes, las performances y otras semejantes -, como formas culturales expresadas en circunstancias históricas determinadas, es decir, históricamente producidas y, también, entendidas. En el tiempo éstas se transforman y dan paso a otras construcciones y formaciones.

Una tercera propuesta es que las representaciones e imaginarios, constituyen expresiones de aquello que Burke denominó “equipamientos para la vida”. En este sentido expresan las diversas prácticas sociales que, por su vez, se insertan en medios sociales en los cuales se presentan como diferentes formas o maneras de hablar, de vestirnos, bailar, cantar, y así sucesivamente; es decir, formas sociales que significan y están a disposición de las personas que las expresan.

Estas propuestas apuntan a un entendimiento de que las representaciones e imaginarios constituyen procesos interculturales e históricamente variables. Así, las representaciones e imaginarios presentes en una determinada sociedad o grupo social, e.gr. la sociedad paraguaya, la argentina, brasileña, en la Triple Frontera o en la sociedad latinoamericana cien años atrás, difieren de aquellas existentes en la misma sociedad cien años después. Estas representaciones e imaginarios tienen y poseen entendimientos distintos en sus descendientes contemporáneos, que por su vez poseen otros imaginarios socialmente construidos. Es importante apuntar que todas estas variantes deben ser aprehendidas a través de la investigación empírica y no pueden ser asumidas a priori. 
Sin embargo, las propuestas y entendimientos citados más arriba llevan todos ellos la marca del pensamiento eurocéntrico - desarrolladas a partir del estudio de sociedades europeas o norteamericanas para las cuales dan respuesta - sustentado por lo que Mignolo denomina la diferencia colonial, es decir, desde una matriz del pensamiento de la modernidad/racionalidad europea. Es necesario pensar desde una matriz otra, desde una perspectiva diferente. El periodismo como practica social, no puede estar fuera de este proceso crítico de emprender nuevos entendimientos y perspectivas al campo. Pensar el periodismo y sus construcciones narrativas desde la diferencia colonial es introducir en esta práctica social un giro epistémico, necesario para repensar el campo desde las fronteras, desde las márgenes. De esta manera esta práctica social asume una significación diferente a aquella que la modernidad dio origen.

\subsection{Representaciones e imaginarios: lo impreso y lo simbólico}

A partir del ya clásico trabajo de Anderson (1997) en el cual desarrolla la relación entre lo impreso y la emergencia del imaginario de nación, varios trabajos e investigaciones han acompañado este camino. Sin embargo, al mismo tiempo se han planteado cuestionamientos al mismo (ORUE POZZO, 2008). Desde esta perspectiva crítica, voy a tratar de impulsar una primera aproximación a la construcción de representaciones e imaginarios en la frontera paraguaya, específicamente Ciudad del Este, como parte de un espacio social más amplio de las Tres fronteras, en la cual convergen otras dos ciudades, Foz do Iguaçu (Brasil) y Puerto Iguazú (Argentina). Sin agotarme en el medio impreso, trataré de introducir una nueva perspectiva acerca de este proceso de construcción de representaciones e imaginarios que un determinado medio de comunicación impulsa en la región. Una primera aclaración a este respecto, es la de apuntar que este proceso no se agota y culmina, bajo ningún sentido, en los medios impresos. La dinámica es mucho más amplia, compleja y por su vez atraviesa varias fronteras culturales expresadas en determinados momentos en relaciones

performáticas, otras en intercambios de mercancías y servicios y, también, en procesos de tensiones simbólicas que se establecen en ciertas situaciones o "actos de verdad" en los intercambios culturales, sociales, económicos y políticos.

Como una obra en construcción, voy a centrarme en este momento en un medio impreso diario, el periódico Vanguardia de Ciudad del Este, Paraguay.

\subsection{Medio impreso en Ciudad del Este}


Ciudad del Este, actualmente con casi 300 mil habitantes - la segunda ciudad en importancia después de la capital del país, Asunción -, según proyecciones de la Dirección General de Encuestas Estadísticas y Censos (DGEEC) de Paraguay. Fue fundada en 1957, como parte de un giro geopolítico paraguayo - y también del Brasil - iniciado en la década de 1940, por el entonces presidente Higinio Morínigo. En agosto de 1941 el entonces, mandatario brasileño, Getulio Vargas visita oficialmente el país. Desde ese momento, y pasando por todo el período de la dictadura cívico-militar de Alfredo Stroessner (1954-1989), Brasil se ha convertido en uno de los países cuyas relaciones la diplomacia paraguaya fue poco a poco privilegiando ${ }^{1}$. Ciudad del Este tuvo varios momentos de cambios y transformaciones: desde la marcha hacia el este, promovida por la dictadura de Stroessner en los años '60 del siglo pasado de manera a tratar de crear una base política y social con la distribución indiscriminada de tierras fiscales a sus aliados, pasando por la inauguración oficial del Puente de la Amistad en marzo de 1965, el inicio de la construcción de la hidroeléctrica de Itaipu, y la presencia de brasiguayos² ${ }^{2}$, la región - y también la ciudad - pasó por varias transformaciones hasta la fecha (Orué Pozzo, 2015, 2014). Situada en la frontera este del país, hoy la región concentra un fuerte foco económico relacionado al agronegocio, principalmente a la producción intensiva de soja. En los últimos años, se desliza un desplazamiento del negocio - y del capital - asociado a artículos electrónicos y otros relacionados a este rubro, para el del agronegocio, cambiando no solamente el rostro de esta ciudad, también su configuración económica, social y cultural.

La ciudad se constituyó inicialmente con una migración paraguaya de distintas regiones del país, para luego dar paso posteriormente a un crisol intercultural: árabes, asiáticos en general, brasileños, argentinos, y la población aborigen originaria de la región. La mayor parte de la población no aborigen - migrantes internos y externos - se dedicó inicialmente al comercio, principalmente de artículos electrónicos. Esta configuración y caracterización de ciudad "comercial" - en el sentido de venta de artículos electrónicos, de belleza, y otros - fue cambiando rápidamente en los últimos diez años. La migración

\footnotetext{
${ }^{1}$ Esto, luego de un largo período pos guerra de la Triple Alianza contra Argentina, Brasil y Uruguay (18641870), cuando recién en julio de 1876, el entonces Imperio de Brasil, retira oficialmente sus tropas de ocupación de territorio paraguayo; desde entonces, el papel principal en las relaciones entre ambos países, pasa a manos de la diplomacia de ese país. Sin embargo, en función a una relación histórica, Paraguay durante mucho tiempo mantuvo una relación de mayor acercamiento con Argentina. El giro que se inicia en los años '40 del siglo XX, continua hasta la fecha.

${ }^{2}$ Forma por la cual se conocen a inmigrantes de origen brasileño - gran parte de los mismos expulsados de sus tierras en Brasil por el proceso de avance de la producción capitalista del agronegocio en el sur de ese país-, que se encuentran en la frontera paraguaya, dedicados principalmente a la agricultura.
} 
configuró a la ciudad como un espacio multi e intercultural, culturas en movimiento que, al entrar en contacto con la paraguaya - incluida la población aborigen -, y entre ellas, tornan a la ciudad - y también a la región - en un espacio social de convergencia cultural tensionada en ciertos momentos, en el cual circulan e interactúan personas, mercancías, flujos culturales y mediáticos. Todo ello configura a la región, y específicamente a la ciudad, como un espacio social de permanentes cambios e intercambios, teniendo como una de las expresiones una cultura híbrida, mezcla de varias configuraciones externas e internas, expresión de tensiones de intercambio.

En 1999, se crea el periódico Vanguardia en Ciudad del Este, convirtiéndose entonces en la primera publicación diaria de la ciudad, y la más importante de la región. Hoy cuenta con una edición diaria de aproximadamente 2.200 ejemplares, distribuidos y vendidos principalmente en la ciudad y parte de los municipios vecinos ${ }^{3}$. Cuenta con 32 páginas, incluyendo tapa y contratapa a color. Es parte del grupo económico encabezado por el periódico de circulación nacional, con sede en Asunción, ABC Color.

\subsection{Aspectos metodológicos}

Para el levantamiento empírico de los datos se ha tomado una muestra en dos momentos, acompañando una línea de investigación cual es la de periodismo en tiempos de crisis y tensiones. Se tomaron dos cortes históricos importantes: i) Uno a nivel internacional que tuvo una repercusión inmediata y fuerte en la ciudad: el atentado a las torres gemelas en setiembre de 2001. ii) El segundo momento: el golpe parlamentario que culminó con la salida de Fernando Lugo de la presidencia y la asunción del entonces vicepresidente, Federico Franco. Este segundo momento, está estrechamente vinculado a la suspensión de Paraguay del Mercosur y de UNASUR, como resultado del juicio político al cual fue sometido el ex Presidente paraguayo, considerado por esos países como un quiebre democrático. Brasil fue, en su momento, uno de los más duros críticos a ese hecho, llamando a su embajador a consultas, situación que se normaliza recién en agosto de 2013, cuando unas elecciones terminan proclamando a un nuevo Presidente, electo en comicios generales en abril de 2013. Brasil, y también Argentina, fue en su momento acusado por sectores de la elite conservadora paraguaya, de intentar re-editar la Triple Alianza de 1865 contra Paraguay, y consecuentemente se desarrolla un tiempo de tensiones y fricciones con estos países, que

\footnotetext{
${ }^{3}$ Datos proporcionados por el director del medio, Nelson Zapata, en entrevista el 16 de julio, 2014.
} 
termina afectando a las fronteras, principalmente a Ciudad del Este, centro comercial importante en el este.

Para efectos del presente trabajo, se han tomado 17 ediciones seguidas de periódico Vanguardia, desde el día siguiente al hecho político que tiene a la investigación como corte temporal. Es decir, se tomaron dos muestras: i) la primera que va del 13 al 29 de setiembre de 2001 (atentado a las Torres Gemelas en Estados Unidos), ii) la segunda muestra, va del 23 de junio al 9 de julio de 2012 (golpe parlamentario contra el ex presidente Fernando Lugo el 22 de junio). Inicialmente se han seleccionado como muestra solamente textos pertenecientes al género de opinión, específicamente editoriales del medio. Estos textos fueron complementados con textos informativos del medio, de manera a tratar de tener una compresión un poco más amplia de la narrativa del mismo en relación al tema de la triple frontera en estudio.

\subsection{Resultados preliminares. Construcciones narrativas y representaciones del medio}

2.6.1 Primer corte temporal: 13-30 de setiembre, 2001.

Como señalaba más atrás, Ciudad del Este congrega una masa importante de ciudadanos de origen árabe y asiático en general ${ }^{4}$. El atentado del 11 de setiembre de 2001 a las torres gemelas de New York, atribuido por el Gobierno de Estados Unidos al grupo terrorista islámico Al Quaeda, afectó profundamente a la comunidad de dicha ciudad, y su entorno. En consecuencia, el hecho se constituyó en un acontecimiento que impactó gran parte de las actividades comerciales - y también cotidianas - de dicha ciudad, pues ciudadanos de fe islámica, y también aquellos de origen árabe, son dueños de una parte importante de los negocios.

En un editorial del 29 de setiembre de 2001, bajo el título de "Triple frontera debe liberarse de la pésima imagen que proyecta", y dado los atentados en New York,

Se aprovechó la oportunidad para relacionar a la capital departamental y las otras ciudades como un lugar donde pululan las denominadas "células islámicas fundamentalistas dormidas". Para colmo, versiones que hasta el propio Osama bin Laden, mentor intelectual de los atentados, ya estaría refugiado en esta parte del país, se hicieron escuchar. Para calentar aun más las cosas, una aparatosa intervención, comandada por enmascarados grupos antiterroristas, levantó tremendo revuelo, causando aun mayor impacto.

El editorial continúa afirmando que medios internacionales e inclusive gobiernos presentan a Ciudad del Este como el "paraíso del Talibán", entre otras cosas, siendo este

\footnotetext{
${ }^{4}$ Foz do Iguaçu también cuenta con una importante comunidad árabe, asimismo de otras regiones de Asia.
} 
imaginario impulsado por "prestigiosos medios de comunicación, como el New York Times, Clarín, O Globo y otros". En estos medios, continua afirmando el editorial de Vanguardia, se habla de Ciudad del Este como un" local ideal para los terroristas", donde éstos "no pueden ser molestados por nadie, donde pueden comprar armas sin restricciones, donde pueden planear sus atentados, etc." Vanguardia cuestiona a los mismos, sosteniendo que no tienen "evidencia física" alguna para tales afirmaciones, apuntando que están causando un tremendo mal a los negocios de la zona, y también "creando una especie de sicosis entre los moradores y principalmente en los residentes árabes, quienes sin juicio previo ya son tildados de terroristas." A partir de este hecho, el editorial avanzan en un cuestionamiento a los grupos antiterroristas de la policía paraguaya, acusándolos de corruptos, pues "presionan a los comerciantes árabes con que les crearían problemas si es que no aportan, y por otro, bien podrían cerrar los ojos ante la presencia de un posible elemento dudoso, con tal de que la suma sea la correcta." Cuestiona el entendimiento que los medios internacionales tratan de pasar sobre la ciudad en el sentido de que en allí no hay orden, no hay ley, reina la impunidad y vale todo. Llega a cuestionar un texto de un periodista argentino en el cual afirma que en Ciudad del Este es posible comprar una bazuca en la calle. Al cuestionar estas visiones desde "afuera", señala sin embargo, que es el Estado paraguayo el que debería controlar, ordenar y reprimir todas las posibles ilegalidades, caso ellas existan. En esta línea de cuestionar al Estado paraguayo afirma que,

No se puede aguardar entonces que la imagen que proyecta Ciudad del Este hacia el exterior sea positiva con estos elementos en contra. El Gobierno Nacional debe dar una atención especial a esta región, así como ahora lo están haciendo Brasil y Argentina, quienes, desde los atentados demostraron un creciente interés por la Triple Frontera.

El editorial del diario Vanguardia concluye sosteniendo que: "En síntesis, si no se respeta la ley y no se la hace cumplir, a nadie debe extrañar que Ciudad del Este y la triple frontera sea por muchas décadas aún, el paraíso del narcotráfico, del contrabando, de la piratería...y del terrorismo."

Es importante señalar que en dicho momento, el municipio de Ciudad del Este, asimismo ciertas agencias del Estado paraguayo, se encontraban implementando acciones tendientes a combatir la ilegalidad, sea en el comercio - aquellos que no contaban con patente municipal y consecuentemente no abonaban impuesto al fisco paraguayo -, asimismo en el caso de trabajadores brasileños empleados sin condiciones legales en el país, lo cual contribuía a una explotación de la fuerza de trabajo con extensas jornadas fuera de los límites 
establecidos por la legislación paraguaya. Así, un editorial de fecha 28 de setiembre de 2001, que lleva por título "Flexibilización de control a ilegales es una puerta para la coima", Vanguardia sostiene que la medida en relación a las situación del comercio ilegal en la ciudad aceptada "por el Gobierno, a través de la persona del viceministro del Trabajo, para flexibilizar los controles de la mano de obra ilegal, huele a negociado, a coima y a transa.” El medio insiste en "aplicar" la ley con mayor rigurosidad. Concluye sosteniendo que "nuevamente no se cumple la ley en toda su extensión, sino es empleada con mano blanda y débil, como siempre se ha hecho."

En un momento, y frente a la crisis desatada debido a la fuerte presión sobre los comercios ilegales y el control de la fuerza de trabajo en situación irregular - principalmente de brasileños -, el Estado llega a sacar a las Fuerzas Armadas a la calle para apoyar en cuestión de seguridad. Ante esta situación, el medio reacciona nuevamente y, en un editorial del 27 de setiembre, sostiene que la "Antipática presencia de las FF.AA en las calles se vuelve insostenible." Observa que inicialmente la justificativa de la presencia de las FF.AA. en las calles de Ciudad del Este, "era debido a los atentados ocurridos en EE.UU." Más adelante pregunta ¿cuál sería la función de los militares?: “Salvarnos de los terroristas? Como ya señaláramos en otras oportunidades, nadie puede ser tan torpe a punto de creen que, con hacer barreras en las calles y controlar colectivos y vehículos, se puede detectar la presencia de terroristas internacionales." El texto sostiene que lo único que logró la presencia del ejército en las calles es crear zozobras, malestar y pánico en las personas y en el comercio de Ciudad del Este. El editorial de Vanguardia termina afirmando:

Si el Gobierno no retira las FF.AA de las calles, la ciudadanía continuará viviendo este clima de zozobra y angustia. Muy al contrario de lo que se podría pensar, no existe clima de tranquilidad y seguridad con los militares en las calles, sino todo lo contrario. Sólo resta esperar que nuestros gobernantes se iluminen pronto y se percaten de esta situación, que ya se está volviendo insostenible para la ciudadanía de Ciudad del Este.

El periódico también da cuenta de los procedimientos realizados por el ejército argentino en la frontera que, ante el temor de la presencia de grupos terroristas de origen islámico en esta región, "realiza una operación de guerra en la región de Tres Fronteras". Pero no solamente el ejército, también la fuerza aérea argentina está presente en este operativo militar. Igualmente, el medio destaca la presencia del ejército brasileño en el puente de la Amistad. Es decir, la zona de fronteras entre los tres países, luego del atentado terrorista a las torres gemelas, se constituyó en una verdadera operación de guerra, construyendo 
representaciones e imaginarios asociados a estas actividades de búsqueda de terroristas islámicos. Todos estos controles militares afectan, sin lugar a duda, al turismo y a los negocios en la región. El comercio exterior por Ciudad del Este "está parado en un 80 por ciento", destacaba una información publicada el 25 de setiembre de 2001.

Finalmente es posible constatar que gran parte de la crítica del medio se orienta a la corrupción que existe en las fuerzas antiterroristas del Gobierno paraguayo. El 26 de setiembre de 2001, en un editorial expresa que el "Gobierno debe desterrar corrupción de los grupos antiterroristas". Con esto apunta que dichos grupos de combate al terrorismo no pasan de ser agencias de recaudación, pedidos de coimas, profundizando de esta manera la corrupción, sosteniendo que los responsables del terrorismo son los propios antiterroristas, quienes han montado un esquema de presión y chantaje a comerciantes de la ciudad. Exige que se investigue, se denuncie y desenmascare a estas fuerzas antiterroristas que operan en Ciudad del Este. Apunta la necesidad de aclarar la situación "con una investigación” que descubra estas acciones. Finaliza afirmando que, "Los EUA también agradecerían un gesto de esta naturaleza ya que actualmente son los máximos interesados en desterrar del mundo el terrorismo."

De esta manera es posible constatar que, en los textos analizados entre el 13 y el 29 de setiembre de 2001, Vanguardia cuestiona directamente los imaginarios y representaciones elaborados por los medios internacionales, entre los cuales cita el New York Times, Clarín y $O$ Globo. Lo contrapone otra construcción narrativa, la de negar que exista terrorismo en esta frontera - y lo demuestra -, aunque sí reconoce que existe una gran debilidad del Estado por controlar al comercio y a la fuerza de trabajo brasileña empleada en los establecimientos comerciales del micro centro de la ciudad. Al contraponer la construcción narrativa y negar la existencia de un terrorismo - y de terroristas - en Ciudad del Este, el medio reconoce y construye un imaginario de corrupción, ilegalidad y precariedad bajo el cual funciona el comercio en la ciudad, gran parte de éstos de propiedad de brasileños y de ciudadanos árabes, que emplean a brasileños, sin cumplir la legislación paraguaya. Dedica una parte importante de las informaciones asociadas al género noticias, a afirmar estas posturas desarrolladas en los textos de opinión editorial del medio. Así, en entrevistas y declaraciones de diplomáticos árabes, de comerciantes de este origen, asimismo descripciones de la ciudad en general, contrapone la construcción de ciudad-terrorista desarrollada por los medios impresos internacionales, con una narrativa que, en su proceso de redacción introduce un sesgo de simpatía y apoyo a los comerciantes y ciudadano de origen árabe, ante las acusaciones de 
terroristas. Vanguardia no solamente cuestiona la narrativa de los medios internacionales, también de los medios nacionales, "principalmente de la capital" (Asunción), destacando que en la ciudad se ha desatado una "injustificada caza de brujas". No existen terroristas en Ciudad del Este, sostiene en gran medida el medio analizado, aunque sí reina una gran corrupción.

Como señalaba más arriba, Vanguardia pertenece al grupo económico que controla también el mayor medio de circulación impreso del país, ABC Color. En consecuencia, gran parte de sus materiales que implicaban consideraciones a nivel nacional, llevaban la impronta del ABC Color, medio de circulación nacional. Es en la localidad de los textos de Vanguardia donde ganaban fuerza contenidos y narrativas en función a lo específico de Ciudad del Este y su frontera con Brasil y Argentina. Es decir, en los bordes y márgenes donde surge la crítica y las experiencias otras en términos de narrativa periodística.

\subsubsection{Segundo corte temporal: 23 de junio al 9 de julio de 2012}

Poco más de diez años después del primer corte temporal seleccionado, el mapa político, social y económico cambio totalmente en el país. El grupo económico familiar que controla $A B C$ Color, también dueño del diario Vanguardia, se volcó de lleno en un apoyo al golpe parlamentario contra el entonces presidente Fernando Lugo. Y estas narrativas estuvieron presentes en Vanguardia, con la diferencia que también da la localidad de los textos.

La narrativa del medio se orienta hacia una construcción textual a partir de materiales informativos, antes que artículos editoriales como fue una característica del corte anterior estudiado. En material de tapa del 27 de junio de 2012, que luego continúa en el texto editorial sostiene que Ciudad del Este está afectada por la crisis,

El convulsionado momento político que vive el Paraguay, tras la destitución del ex presidente Fernando Lugo, también afectó al comercio de CDE. No obstante, los empresarios locales consideran que los factores coyunturales en el mercado europeo y las trabas brasileñas y argentinas causan más estragos que la situación política que actualmente soporta el país.

El titular de dicha editorial apunta: "Hipocresía internacional respecto a la situación del Paraguay debe acabar" (Editorial, 27 de junio, p. 4). El texto hace referencia principalmente a la postura de Brasil - a la que también se suma Argentina -, que es uno de los países que con mayor énfasis cuestionó los procedimientos que llevaron a la salida de Fernando Lugo de la presidencia del país, vía juicio político. El "convulsionado momento 
político también afectó al comercio esteño", señala el artículo editorial del 27 de junio. En general, ésta fue la tónica del discurso narrativo del medio estudiado.

A pocos días del desenlace del golpe parlamentario del 22 de junio, Vanguardia destaca y enfatiza la situación en las tres fronteras que afecta, básicamente, al movimiento comercial. En un texto publicado el 2 de julio, se lee,

A varios días del juicio político que causó la destitución de Fernando Lugo y tras las consecuencias del hecho logramos conversar con algunos comerciantes en Ciudad del Este, sobre la situación actual en el país. En su mayoría concordaron que el movimiento comercial se redujo notablemente después de la decisión del Senado. Afirman que muchos de los turistas prefieren no cruzar el puente de la amistad. ...Según los informes de los comerciantes, los turistas se asustaron por la situación y prefieren no arriesgarse a cruzar el puente de la Amistad...Los trabajadores en su mayoría afirmaron que la situaciones crítica debido a la nula presencia de los sacoleiros y turistas. El fin de semana se podían ver las galerías y negocios vacíos así como las avenidas y calles con poco movimiento. Esta situación también castiga a los trabajadores informales, que indicaron que en algunos días no venden absolutamente nada y que no salvan ni siquiera sus pasajes.

Finalmente, citamos otra llamada en tapa el 25 de junio de 2012. Allí, Vanguardia introduce el tema de los "brasiguayos", quienes en un determinado momento, y frente a la situación irregular de las tierras que ocupan, se sintieron amenazados por las movilizaciones campesinas que cuestionaban esta situación, principalmente aquellas asociadas a grandes propietarios de origen brasileño. En los días posteriores al golpe parlamentario, éstos solicitan al gobierno de Brasil, el urgente reconocimiento al nuevo gobierno paraguayo encabezado por Federico Franco, ex vicepresidente de Fernando Lugo:

Productores y cooperativistas brasiguayos (descendientes de brasileños) se reunieron ayer con el cónsul brasileño en Ciudad del Este, Flavio Roberto Bonzanini, para solicitar la intermediación de éste ante Itamaraty, a fin de lograr el "reconocimiento inmediato" del nuevo Gobierno paraguayo, encabezado por Federico Franco. Los productores responsabilizan a Fernando Lugo del clima de "guerra" que imperaba últimamente en el campo y creen que con Franco finalmente se dará un paso decidió hacia la pacificación.

Inclusive la Junta Departamental - órgano de Gobierno legislativo de la Gobernación de Alto Paraná, cuya capital es Ciudad del Este -, solicita al Gobierno brasileño el reconocimiento oficial del Gobierno Franco.

Como es posible observar, gran parte de la estrategia narrativa del diario Vanguardia, está asociado el tema de las relaciones bilaterales Paraguay-Brasil, principalmente; aunque también en algunos momentos introducen también a la Argentina. Sin embargo, los textos se 
orientan hacia una crítica a Brasil en función al no reconocimiento del Gobierno de Federico Franco, quien asume luego del juicio político al entonces presiente Fernando Lugo. El espacio social de las tres fronteras es presentado y construido como un espacio comercial que queda afectado debido al hecho que Brasil no reconoce al Gobierno paraguayo que surge del golpe parlamentario en junio de 2012. Las relaciones con Brasil, asimismo las relaciones de los denominados brasiguayos, son narradas en este contexto político: es urgente que Brasil regularice sus relaciones diplomáticas con Paraguay, pues el comercio y la población de Ciudad del Este, está afectada por esta actitud del país vecino. Para tal efecto los textos impulsan una estrategia de colocar y visibilizar a todos aquellos que de alguna manera desarrollan un discurso de conciliación con Brasil - asimismo de crítica a la diplomacia brasileña - sean éstos comerciantes de la ciudad, productores asociados al agronegocio, políticos de la ciudad y de Brasil, y también medios de comunicación locales y nacionales. En este sentido no existe una clara separación entre lo local y lo nacional en las construcciones narrativas del diario Vanguardia, salvo en lo relativo a la visibilización de autoridades locales y de la región, asimismo productores asociados al agronegocio que en los últimos 15 años emergen como uno de los grandes agentes económicos y políticos en Paraguay. En ningún momento se cuestiona o se levantan aspectos relacionados a la corrupción, ilegalidad, y otros temas presentes en el corte temporal anterior.

\section{CONCLUSIÓN}

Es posible observar un cambio en la construcción discursiva del medio impreso de Ciudad del Este analizado entre los dos eventos investigados. En setiembre de 2001, en los textos analizados, el énfasis estaba colocado en la propuesta de construir una tradición distinta a aquella que los medios internacionales e, inclusive, nacionales pasaban en relación a ciertos temas de las tres fronteras como terrorismo y presencia de grupos islámicos radicalizados, a partir de los atentados a las torres gemelas en New York. Vanguardia desarrolla una estrategia para contraponer esta construcción narrativa a otra, asociada no a la presencia de terroristas y grupos islámicos radicalizados, sino más bien al escaso control del Estado paraguayo sobre los espacios de frontera. En este sentido, la narrativa se orienta a destacar la corrupción que atraviesa las diversas instituciones del Estado paraguayo, inclusive aquella incrustada en las propias fuerzas antiterroristas de la policía nacional. Cuestiona a las fuerzas de seguridad - policía y ejército -, que en nada contribuyen a construir un imaginario 
de ciudad segura donde todos se dedican pacíficamente a sus negocios y al turismo. Para el diario Vanguardia, la ilegalidad y la corrupción están asociadas a la débil presencia de las autoridades paraguayas en la región, es decir, a la debilidad del estado-nación. Es por esta razón que ciertos comercios funcionan en la ilegalidad, y también la fuerza de trabajo brasileña trabaja al margen de la legislación laboral paraguaya. Para el medio impreso existe una situación de corrupción e ilegalidad en la zona de frontera paraguaya, pero no existen terroristas. Es decir, los medios de comunicación internacionales construyen un espacio social al exterior del entendimiento de la región, y esto afecta, finalmente al comercio trifronterizo y a las personas que lo habitan.

En junio de 2012, en función al golpe parlamentario que aparta al entonces presidente Fernando Lugo, el medio impreso en estudio, tiene un discurso narrativo diferente. Se centra en las relaciones comerciales, en la problemática que presenta la región en función a la “injusta” suspensión de Paraguay del Mercosur y de UNASUR. En ningún momento destaca o insinúa posibilidades de corrupción o de trabajos en "situación" de ilegalidad. El discurso sobre el terrorismo internacional, no está en ningún momento presente en los textos analizados durante este corte temporal. Es decir, una construcción narrativa distinta a la desarrollada por este medio poco más de diez años atrás. Sin duda alguna, la realidad cambió, y esto se observa también en las páginas del medio.

Lo señalado más arriba me lleva a pensar que, al cambiar y transformarse los contextos en los cuales se insertan la narrativa periodística, esta también cambia y se adapta a lo nuevo. Hasta aquí lo apuntado sería una verificación obvia. Pero, considero que aquello que está realmente en discusión en los procesos estudiados es, hasta qué punto y sobre todo el alcance que tiene el medio en el desarrollo de una nueva tradición asociada a Ciudad del Este. No aquella relacionada al terrorismo, no aquella relacionada a grupos islámicos radicalizados, sino a otra que es posible "administrar", pues involucra al Estado paraguayo: el combate a la corrupción y a la ilegalidad en esta región. Pero, esto también cambia y se transforma. De una crítica a la corrupción y a la ilegalidad, Vanguardia pasa a una narrativa que se aleja de estos constructos, introduciendo otro nuevo, relacionado a la necesidad que las fuerzas productivas sean las que definan y construyan las relaciones bilaterales e internacionales en el país. Son los brasiguayos, pero no cualquier brasiguayo, mas aquel gran productor inserto en el agronegocio que estructura nuevas relaciones sociales en la región. Todos deben compactarse para defender la ciudad, para defender los negocios, para que las relaciones comerciales y los intercambios se desarrollen de la forma y manera esperadas, es decir, que continúen 
produciendo el lucro esperado. Al final de cuentas, este aspecto constituye una de las representaciones de Ciudad del Este, construida a lo largo de los últimos años en este medio de comunicación.

Esto me lleva a destacar que los conocimientos creados, manufacturados y desarrollados en países del Norte, no son, como tampoco pueden ser, universales. Sin embargo, para los medios de comunicación de estos países, la narrativa impulsada desde los mismos - al igual que la ciencia impulsada desde países del Norte - es universal, y deben imponerse como modelo a seguir por parte de países del Sur global. Lo que emerge en este sentido, es que existen conocimientos locales, conocimientos totalmente ignorados, subaltenizados y destacados como inferiores por países hegemónicos, que tienen otra dinámica y otra lógica en su desarrollo. Y los medios de comunicación constituyen un buen ejemplo de cómo y de qué manera subaltenización se manifiesta en la práctica.

De esta manera, este giro narrativo, giro en cuanto a la diferencia colonial que apuntaba más arriba, debe ser planteado y desarrollado en el contexto de una hegemonía discursiva del momento: el juicio político a Fernando Lugo, y las reacciones que este procedimiento suscitó en el país, asimismo en la región. Brasil y Argentina (Tres Fronteras) fueron los países más firmes en las sanciones a Paraguay, suspensión del Mercosur y de Unasur. La narrativa del medio gira en torno a los aspectos políticos de las relaciones Paraguay-Brasil, y cómo y de qué manera esto afecta a los negocios, al comercio, en la región. Y esto introduce la cuestión del estado-nación que se conforma y construye en América Latina - y en Paraguay - pos colonial. Una independencia política de las élites criollas para que éstas ejerzan la intermediación con las élites del imperio. Y este estado nación fue construido excluyendo a poblaciones indígenas, mujeres, afro descendientes, grupos con identidades sexuales diferentes a la heterosexual. Es lo que el periódico Vanguardia expresa en sus textos en el segundo corte temporal, al afirma que son los productores - es decir, los grandes propietarios de tierra asociados al agronegocio - quienes deben orientar las relaciones y la política en el país.

La colonialidad de los textos y narrativas producidas en países hegemónicos en el cual destacan las inferioridades de las poblaciones de países fuera de dicho eje, y que deben ser civilizados por las ideas y prácticas europeas y norteamericanas, están sumamente presente en medios analizados. De esta manera la Triple Frontera es construida a partir de esta diferencia colonial. Es necesario entonces, una nueva narrativa, una nueva opción desde lo local, desde este locus de enunciación narrativa. 


\section{REFERENCIAS}

ANDERSON, Benedict. Comunidades imaginadas. México: FCE, 1997.

BAUMAN, Richard. Introduction. En Richard Bauman (Ed.) Folklore, cultural performances, and popular entertainments, New York: Oxford University Press, 1992.

BIDASECA, Karina \& VAZQUEZ LABA, Vanesa. Feminismo y poscolonialidad. Descolonizando el feminismo desde y en América Latina. Buenos Aires: Godot, 2013.

BUTLER, Judith. Cuerpos que importan. Buenos Aires: Paidós, 2008.

DIRECCION GENERAL DE ENCUESTAS ESTADISTICA Y CENSO. Proyección de la población distrital. http://www.dgeec.gov.py/ Consulta: 8 de octubre de 2016.

DOMINGUEZ, Manuel. El alma de la raza. Buenos Aires: Ayacucho, 1948.

GONZALEZ, Juan Natalicio. El Paraguay eterno. Asunción: Guarania, 1935.

GOLUBOV, Nattie. La teoría literaria feminista y sus lectoras nómadas. Revista

Discurso, Teoría y Análisis, n. 31, p.1-9, 2011.

LOPEZ, Miguel. Los silencios de la palabra. Asunción: ServiLibro, 2003.

MIGNOLO, Walter. Historias locales/diseños globales. Madrid: Akal, 2003.

MONTENEGRO, Silvia. \& GIMENEZ BELIVEAU, Verónica. La Triple Frontera: Globalización y Construcción social del espacio. Buenos Aires: Miño y Dávila, 2010.

ORUE POZZO, Aníbal. Años de plomo y margaritas: las relaciones Paraguay-Brasil y el camino hacia el Este. En: A. ORUE POZZO (Org.) Relaciones Bilaterales Paraguay-Brasil: sociedad, economía y cultura. Ciudad del Este: UNE-Escuela de Posgrado, 2015.

Paraguay y sus fronteras. En D. ARAUJO PEREIRA. Cartografía imaginaria da Tríplice Fronteira. São Paulo: Dobra Universitaria, 2014.

Periodismo y nación. Asunción: Arandura, 2008. 
Possui posdoutorado em Comunicacao e Estudios Sociais de Fronteira, Centro de Estudos Avancados /CEA, Universidad Nacional de Córdoba, doutorado em Aministración - Procesos Comunicacionales Universidad Autonoma de Asuncion (2003) e Mestrado em Estudos de Midia, New School for Social Research University, New York. Atualmente é docente de la Universidad Federal de la Integración Latino Americana (UNILA), com ênfase em Comunicação, cultura e territorios.

Esta obra está licenciada sob uma Licença Creative Commons. 